\title{
Dordtse Leerregels actueel: discussies, structuren en motieven
}

\author{
R.T. te Velde
}

\begin{abstract}
This article addresses the continuing validity and relevance of the 400 year old confessional statements published by the Synod of Dordt (1618-19). It discusses continuities and differences at three levels: (1) the debates of the early $17^{\text {th }}$ century on questions concerning divine sovereignty and grace versus human responsibility and free choice; (2) the conceptual structures that underlie the exposition of doctrine in the Canons, and that express the necessary connections between God's eternal and unconditional decree, atonement through Christ's death, the powerful work of the Holy Spirit in regeneration, and the perseverance of the saints; and, (3) the Christological, Biblical, pastoral, and ecclesiological motives that permeate the doctrinal statements.
\end{abstract}

Zijn de Dordtse Leerregels nog actueel? De herdenking van 400 jaar Dordtse synode is een goede aanleiding om bij die vraag stil te staan. Wellicht zouden we eerder zeggen: onbekend maakt onbemind. Voor een belangrijk deel ligt dat aan het onderwerp: de leer van uitverkiezing en verwerping. Het predestinatiegeloof lijkt een van de meest twijfelachtige vruchten van het calvinisme. In de geschiedenis van kerk en vroomheid die op Dordt is gevolgd, raakte men met de Leerregels in de hand soms op dood spoor. ${ }^{1}$ Het filosofisch en cultureel klimaat van vandaag verschilt fors van dat aan het begin van de $17^{\mathrm{e}}$ eeuw. Het spreken over verkiezing en verwerping roept bij velen verlegenheid en vervreemding op. De reflex kan dan zijn, om er maar ver bij vandaan te blijven, en in de praktijk van verkondiging en pastoraat vooral te spreken over Gods beloften in het evangelie, over de genade die God zonder enige

1 Voor een literaire expressie van de problematiek die het 'verkiezingsgeloof' in de gereformeerde gezindte heeft opgeroepen, zie het werk van auteurs als Maarten 't Hart en Jan Siebelink. Een uitgebreid theologie-historisch overzicht van alle vertakkingen van de debatten over predestinatie en geloofszekerheid is te vinden bij K. van der Zwaag, Afwachten of verwachten? De toe-eigening des heils in historisch en theologisch perspectief, Heerenveen 2003. Prof. C. Graafland wijdde enkele belangrijke studies aan de zijns inziens aanwezige spanning tussen verkiezing en verbond in de gereformeerde traditie: Van Calvijn tot Barth. Oorsprong en ontwikkeling van de leer der verkiezing in het Gereformeerd Protestantisme, 's-Gravenhage 1987, en Van Calvijn tot Comrie. Oorsprong en ontwikkeling van de leer van het verbond in het gereformeerd protestantisme, Zoetermeer 1992-1996. 
reserve aanbiedt en die we daarom ook vrijmoedig mogen aannemen.

In dit artikel wil ik betogen dat de Dordtse Leerregels een blijvende actualiteit hebben. Die komen we juist op het spoor als we ons bewust zijn van het verschil tussen de context waarin ze zijn ontstaan en de huidige tijd en cultuur. In dat verschil kunnen we namelijk ook de continuïteit ontdekken die het mogelijk maakt om in de vertolking van het evangelie het spoor te blijven volgen dat de gereformeerde kerk in Nederland - met steun en instemming van de gereformeerde kerken uit andere Europese landen - trok in de confrontatie met de remonstranten. ${ }^{2}$ Op drie niveaus kunnen we de beweging van toen naar nu maken: ten eerste door te letten op de discussies die in de Leerregels aan de orde zijn; ten tweede door de begripsmatige en argumentatieve structuren te bekijken; ten derde door enkele motieven te bekijken die door de uiteenzetting in de Leerregels heen spelen. ${ }^{3}$

\section{Discussies}

In de discussies die in de Dordtse Leerregels aan de orde zijn, zien we het meest directe verband met de tijd en situatie waarin de Canones zijn ontstaan. De Leerregels komen niet uit de lucht vallen, maar ze vormen de afsluiting van een strijd die in ieder geval sinds 1604 de Nederlandse kerk in de greep hield. In feite bestond een fundamenteel verschil van visie over de leer van de uitverkiezing al vanaf het begin van de gereformeerde kerk in de Noordelijke Nederlanden, maar de disputen aan de Leidse universiteit tussen Jacobus Arminius en Franciscus Gomarus werkten als een katalysator. ${ }^{4}$ Als wij de

2 De vraag naar continuïteit en verschil in onze receptie van de Dordtse Leerregels is een specificatie van de hermeneutische vraag: in hoeverre is de verwoording van de gereformeerde leer contextueel bepaald, en hoe gaan we daar in een veranderende context mee om? De vooronderstelling van mijn betoog is dat het waarnemen van een verschil in context geen bedreiging van inhoudelijke en leerstellige continuïteit hoeft te zijn, maar juist kan helpen om te bepalen waar deze continuïteit ligt en hoe zij in taal en beleving van vandaag kan worden uitgelegd.

3 Citaten uit de Dordtse Leerregels zijn ontleend aan Belijdenisgeschriften van de Protestantse Kerk in Nederland, K. Zwanepol, C.H. van Campenhout red., Heerenveen 2009.

4 W. Verboom, De belijdenis van een gebroken kerk. De Dordtse Leerregels - voorgeschiedenis en theologie, Zoetermeer 2005, geeft een uitvoerige schets van het verloop van de arminiaanse controverse tot en met de Dordtse synode. Voor een analyse van inzet en motieven van Jacobus Arminius, zie William den Boer, Duplex Amor Dei. Contextuele karakteristiek van de theologie van Jacobus Arminius (1559-1609), Apeldoorn 2008, en Eef Dekker, Rijker dan Midas. Vrijheid, genade en predestinatie in de theologie van Jacobus Arminius (15591609), Zoetermeer 1993. Over de bijdrage van Franciscus Gomarus aan de debatten ontbreekt helaas een up-to-date wetenschappelijke studie, zodat we op het oudere standaardwerk aangewezen blijven van G.P. van Itterzon, Franciscus Gomarus, ‘s-Gravenhage 1929. 
strijdgeschriften uit die periode lezen, kunnen wij ons erover verbazen hoe de leer van de predestinatie met alle hoge en ingewikkelde vragen die daarin samenkomen zo tot het brandpunt van de theologische discussies kon worden, en hoe daar bovendien allerlei sociale en politieke zaken mee vermengd raakten. We kunnen constateren dat in de setting van de vroege gereformeerde theologie een cluster aan inzichten, benaderingen en vraagstukken aan de orde was dat het verloop en de felheid van de debatten bepaalde. Zouden wij momenteel - even afgedacht van de erfenis van Dordt - dit geheel van de bijbelse leer van genade, verkiezing, wedergeboorte en geloofszekerheid nog op dezelfde manier benaderen als dit in de vroege $17^{\mathrm{e}}$ eeuw gebeurde?

Toch betekent dit niet dat de discussies zoals ze destijds door Gomarus en Arminius en anderen werden gevoerd, in onze dagen achterhaald zijn. Wereldwijd gezien is er in de evangelische beweging nog altijd een levendige tegenstelling tussen calvinisten en arminianen. In de wat vergrovende samenvatting TULIP wordt de leer van Dordt gebruikt om kerkelijke en theologische grenzen af te bakenen. ${ }^{5}$ Dat binnen dit spectrum allerlei varianten en onverwachte combinaties voorkomen, doet niets af aan het besef dat in de vragen rond menselijke autonomie en verantwoordelijkheid aan de ene kant en goddelijke genade en soevereiniteit aan de andere kant wezenlijke stukken van het christelijk geloof op het spel staan.

De debatten die in de vroege $17^{\mathrm{e}}$ eeuw de kerk verscheurden, waren niet willekeurig. Binnen het speelveld van de gereformeerde theologie die zich op Calvijn, Beza en anderen oriënteert, komt in verscherpte vorm een thematiek aan de oppervlakte die op dat moment overal sluimert. Recent onderzoek heeft opvallende parallellen laten zien met de zogenoemde Gnadenstreit oftewel de Controversia de auxiliis in de Rooms-Katholieke Kerk van die dagen. ${ }^{6}$ Terwijl de Reformatie de onvoorwaardelijke genade van God opnieuw ontdekte, maakte zich tegelijk een levensgevoel breed dat de menselijke

5 Het acrostichon TULIP staat voor: Total depravity - Unconditional election - Limited atonement - Irresistible grace - Perseverance of the saints. Een voorbeeld van actueel debat tussen arminianen en calvinisten is te vinden in Roger Olson, Against Calvinism, Grand Rapids 2010, en Michael S. Horton, For Calvinism, Grand Rapids 2011.

6 Zie bijvoorbeeld Gijsbert van den Brink, Dordt in context. Gereformeerde accenten in katholieke theologie, Heerenveen 2018, hoofdstuk 6; Robert Joseph Matava, Divine Causality and Human Free Choice: Domingo Báñez, Physical Premotion, and the Controversy De Auxiliis Revisited, Leiden-Boston 2016; Richard A. Muller, Divine Will and Human Choice: Freedom, Contingency, and Necessity in Early Modern Reformed Thought Grand Rapids 2017. 
mogelijkheden en waardigheid hoog in het vaandel had. De overgang van de $16^{\mathrm{e}}$ naar de $17^{\mathrm{e}}$ eeuw is kerkelijk gezien de fase van confessionalisering. ${ }^{7}$ Bezien vanuit de bredere ontwikkelingen in filosofie en levensbesef is diezelfde periode de definitieve overgang van Middeleeuwen naar moderne tijd. Ondanks alle schommelingen rond laatmoderne en postmoderne uitschieters hebben we in de basishouding nog altijd een moderne cultuur in WestEuropa. Ondergronds lopen de verbindingen over een afstand van vier eeuwen door, en is er veel continuiteit in het levensgevoel. ${ }^{8}$ De remonstranten waren een voorbode van de moderne mens.

Een van de belangrijkste ontwikkelingen die in de tussenliggende eeuwen heeft plaatsgevonden, is de enorme subjectivering die principieel bij Descartes begonnen is, zich vervolgens in de hele filosofie van de Verlichting sterk gemaakt heeft tegenover elke binding aan autoriteit en instituut, en die in onze tijd invulling krijgt in een volstrekt psychologisch en moreel individualisme. Deze psychologisering laat het grootste verschil zien ten opzichte van de strijd die remonstranten en contra-remonstranten voerden. Bij Arminius en de zijnen wordt de nadruk op het vrije menselijke subject tamelijk rationeel en intellectueel ingevuld: als God ons maar duidelijk vertelt hoe we ervoor staan, dan zullen we wel vanzelf de juiste keuze maken. ${ }^{9}$ De tegenwoordige mens is veel ingewikkelder en chaotischer geworden, en drijft veel meer op irrationele emoties. Juist in dat laatste opzicht bevatten de Dordtse Leerregels een belangrijk tegoed, omdat zij niet meegaan in de optimistische,

7 Zie voor het concept 'confessionalisering' H.J. Selderhuis (red.), Handboek Nederlandse kerkgeschiedenis, Kampen 2010, 221-223 en 395-397.

8 Een invloedrijke duiding van de laatste paar eeuwen westerse cultuurgeschiedenis is gegeven door Charles Taylor, A Secular Age, Cambridge, Mass. 2007.

9 Dit aspect van Arminius' theologie kan geplaatst worden in het kader van de zogeheten faculteiten-psychologie die in de vroegmoderne filosofie gangbaar was. De vermogens ('faculteiten') van de menselijke ziel zijn het verstand waarmee gekend wordt, de wil die kiest, en de macht waarmee men deze keuze kan uitvoeren. In deze aan Aristoteles ontleende indeling spelen de gevoelens/emoties geen zelfstandige rol, doorgaans worden ze meegerekend met de wil. Volgens Arminius en de zijnen werkt Gods genade vooral in op het menselijk verstand, en volgt dan de wil min of meer automatisch. Zie hiervoor Aza Goudriaan, 'The Synod of Dordt on Arminian Anthropology', in: Aza Goudriaan en Fred van Lieburg (red.), Revisiting the Synod of Dordt (1618-1619), Leiden-Boston 2010, 81-106. De contraremonstranten legden nadruk op een veel sterkere en directe inwerking van de Heilige Geest op de wil van de mens, en zo is het ook in de Dordtse Leerregels (hoofdstuk III/IV) terechtgekomen. 
rationele visie van de remonstranten, maar veel meer oog hebben voor wat er in de diepere lagen van ons mens-zijn gebeurt wanneer God met zijn genade binnenkomt. Hier zie ik een uitdaging voor gereformeerde theologie, om aan de hand van de Dordtse Leerregels die diepte van wil en emotie aan te boren, en mensen van vandaag aan te spreken op wat zij als de realiteit van hun leven ervaren, vaak zonder dat zij God erbij betrekken.

Een laatste element als het gaat om de discussies die aan de orde zijn in de Dordtse Leerregels, is dat het erop lijkt dat mensen vandaag minder geïnteresseerd zijn in God en in wat er tussen hen en God gebeurt. De hele thematiek van verkiezing - verlossing - wedergeboorte lijkt voor velen steeds minder relevant. Positieve en betrokken christenen lijken zich niet druk te maken over hun persoonlijke zielenheil, maar willen zich vooral inzetten voor de doorwerking van Gods gerechtigheid in deze wereld. De theologie van N.T. Wright en anderen poneert het 'koninkrijk van God' als het nieuwe overkoepelende perspectief. Daarin telt veel minder de individuele vraag 'hoe krijg ik een genadig God?', en veel meer de universele vraag 'wat gebeurt er als God koning wordt?' 10 Het laat zich gemakkelijk uittekenen hoe in dit nieuwe kader de leer van de uitverkiezing óf naar de achtergrond verdwijnt óf een ingrijpende herziening en verbreding ondergaat. Deze verschuiving in de discussie is zo mogelijk nog verstrekkender dan de inhoudelijke wijziging van standpunten: als voor het besef van velen de aandacht voor de 'binnenkant' van de heilsleer sowieso achterhaald en ongezond is, dan valt van de Dordtse Leerregels weinig heil te verwachten. Het is echter de vraag of we zonder die binnenkant kunnen: in het koninkrijk van God gaat het toch ook om burgers die hun eigen wil leren prijsgeven en de wil van God, die alleen goed is, zonder enig tegenspreken leren gehoorzamen (Heidelbergse Catechismus, vraag en antwoord 124). Daarvoor is de radicale vernieuwing van onze wil in de wedergeboorte onmisbaar.

\section{Structuren}

Het volgende niveau waarop we naar de actualiteit van de Dordtse Leerregels kijken, is het niveau van structuren. Daarbij kunnen we denken aan begrips-

10 Onder de vele boeken die Wright gepubliceerd heeft, valt hier te wijzen op N.T. Wright, How God became King, Londen 2012. In Nederland wordt dit gedachtengoed uitgewerkt door onder anderen Ronald Westerbeek, Feest van het Koninkrijk: Een verdiepend gemeenteproject rond het Onze Vader, Amsterdam 2016. 
matige kaders, aan samenhang tussen de verschillende onderdelen, en aan logische gevolgtrekkingen die gemaakt worden. In dat opzicht staan de Leerregels als confessie wat apart. Ook de andere belijdenisgeschriften bevatten theologische begrippen en onderscheidingen, maar in de Dordtse Canones zijn die explicieter en komen ze meer aan de oppervlakte. Vooral in de 'Verwerping der dwalingen' wordt met exacte terminologie en onderscheidingen gewerkt. Voor een groot deel is dit te verklaren vanuit de toen actuele discussies. Gomarus en Arminius waren beiden hoogleraar theologie, en gebruikten het fijn uitgewerkte instrumentarium van de scholastieke theologie. Het debat tussen deze twee laat overigens zien dat 'scholastiek' niet als zodanig tot een bepaalde opvatting of leersysteem leidt, maar alleen helpt om tot een heldere formulering van de punten in geding te komen en om verantwoording te geven van de eigen visie. ${ }^{11}$

In vijf hoofdstukken geven de Dordtse Leerregels een samenhangende leer over het heil, waarbij ze ingaan op vragen als:

- Waar komt het vandaan dat de een wel gelooft en de ander niet?

- Hoe wordt de verzoening door het offer van Christus ons deel?

- In hoeverre kunnen mensen vanuit zichzelf het goede doen en zich tot God bekeren?

- Wat is wedergeboorte?

- Kunnen mensen het zaligmakend geloof verliezen?

Zoals bekend, is de indeling in vijf hoofdstukken ontleend aan de vijf punten uit de Remonstrantie van 1610. Dordt reageert op de verwijten die door volgelingen van Arminius aan de gereformeerde theologie van Calvijn en Beza werden gemaakt. ${ }^{12}$ Het belangrijkste verwijt komt in het Slotwoord nog eens naar voren: 'Dat deze leer God tot een auteur van de zonde maakt, onrechtvaardig, een tiran en huichelaar'. In de beleving van velen is dit nog altijd het meest problematische aspect van de gereformeerde leer van verkiezing en

11 Voor een introductie in de scholastieke vorm van gereformeerde theologiebeoefening, zie W.J. van Asselt e.a., Inleiding in de gereformeerde scholastiek, Zoetermeer 1998; bijgewerkte Engelse vertaling: Introduction to Reformed Scholasticism, Grand Rapids 2011.

12 In feite komen de meeste verwijten aan de calvinistische predestinatieleer al voor in de 'Verklaring van gevoelen' van Arminius zelf, nog vrij onlangs in een Engelse vertaling uitgebracht door W. Stephen Gunter, Arminius and his 'Declaration of Sentiments': An Annotated Translation with Introduction and Theological Commentary, Waco 2012. 
verwerping: als Gods besluit allesbeheersend is, zijn wij dan nog wel zelf verantwoordelijk voor de zonde die wij doen? Heeft God de wereld geschapen om vervolgens het grootste deel van de mensheid tot de eeuwige ondergang te bestemmen? Vooral in de supralapsarische positie, zoals verdedigd door Beza, Perkins en ook Gomarus, lijkt het moeilijk om aan deze consequentie te ontkomen. ${ }^{13}$ De Dordtse Leerregels kiezen in hoofdstuk I, artikel 1 bewust voor een infralapsarische inzet: 'Aangezien alle mensen in Adam gezondigd hebben en de vloek en de eeuwige dood verdiend hebben ...' Dit is de startsituatie, waarin Gods besluit om sommigen tot eeuwig heil te verkiezen des te stralender uitkomt als het grote bewijs van zijn liefde.

Ook valt in zowel het eerste als het laatste hoofdstuk op hoe terughoudend er over de verwerping - als negatieve keerzijde van de verkiezing - wordt gesproken. Het Slotwoord maakt met zoveel woorden duidelijk dat het onjuist is om de gereformeerde leer te interpreteren alsof de verwerping door God op dezelfde wijze de oorzaak is van ongeloof en goddeloosheid als de verkiezing de bron is van geloof en goede werken. Van een ijzeren, deterministische structuur is in de Dordtse Leerregels geen sprake.

Tegelijk blijft een structuur bewaard waarin er een noodzakelijk verband bestaat tussen Gods besluit van verkiezing, de toerekening van de verzoening door Christus, het krachtige werk van de Geest in wedergeboorte en geloof, tot aan de genadige bewaring van de heiligen door alle strijd en zwakheid heen. Het is een structuur die niet door de Leerregels zelf in schema gezet wordt, maar die wel eenvoudig op te pikken is door de hoofdstukken achter elkaar te lezen. Ik spreek over een noodzakelijk verband, niet omdat het uitgekozen of verworpen zijn zelf een noodzakelijke stand van zaken is, maar omdat het gaat

13 De kwestie van het supralapsarisme bij Beza en Perkins wordt uitvoerig behandeld door Graafland, Van Calvijn tot Barth, hoofdstuk 2 en 3. Voor enige nuance, zie Richard A. Muller, Christ and the Decree: Christology and Predestination in Reformed Theology from Calvin to Perkins, 2e druk, Grand Rapids 2008, hoofdstuk IV en VI, en Raymond A. Blacketer, 'The Man in the Black Hat: Theodore Beza and the Reorientation of Early Reformed Historiography', in: Jordan J. Ballor e.a. (red.), Church and School in Early Modern Protestantism: Studies in Honor of Richard A. Muller on the Maturation of a Theological Tradition, Leiden-Boston 2013, 227-241. 
over de manier waarop God zijn heilswerk volvoert. ${ }^{14}$ Een belangrijke veronderstelling van de leer die de Dordtse Leerregels uiteenzetten, is dat God niet willekeurig werkt en niet door onvoorziene omstandigheden verrast wordt. De alwetendheid en wijsheid en almacht van God vormen het kader waarin over Gods handelen wordt gesproken. God weet wat Hij wil, en wat Hij in zijn wijsheid besluit, dat brengt Hij ook daadwerkelijk tot voltooiing.

Terecht is er van verschillende kanten op gewezen dat wat hoofdstuk II leert over de reikwijdte van de verzoening beter met het woord 'effectief' of 'bepaald' (definite) kan worden aangeduid dan met 'beperkt' (in het Engels: limited atonement). ${ }^{15}$ Dat de dood van Christus al diegenen - en hun alleen ten goede komt die door de Vader aan Christus gegeven zijn (II, 8), is om twee diep-bijbelse redenen van belang: ten eerste, omdat het gaat om de bewuste intentie waarmee Christus de kruisdood op zich genomen heeft, uit liefde voor de zijnen; ten tweede, omdat de verlossing door Christus krachteloos zou blijven wanneer het niet vervolgens ook in Góds handen ligt om ons daadwerkelijk met zichzelf te verzoenen. Hetzelfde geldt voor de leer van de wedergeboorte in hoofdstuk III/IV en van de volharding in hoofdstuk V: als dit niet door Gods eigen Geest ter hand genomen wordt, als God er niet zelf met zijn eeuwig besluit borg voor staat, dan komt er niets van terecht. De doorgaande lijn in de Dordtse Leerregels heeft dus alles met het karakter en de realiteit van onze verlossing te maken.

14 In het 'technische' spraakgebruik van de scholastiek-gereformeerde theologie: het gaat hier om een 'noodzakelijkheid van gevolgtrekking' (necessitas consequentiae of hypothetische noodzakelijkheid), niet om een 'noodzakelijkheid van het gevolg als zodanig' (necessitas consequentis of absolute noodzakelijkheid). Om een alledaags voorbeeld te geven: als je buiten in de regen loopt, word je nat. Geen van de elementen in deze zin is op zichzelf genomen noodzakelijk: het hóeft niet te regenen, je hád binnen kunnen blijven, en ook nat worden is op zichzelf niet onvermijdelijk. Maar de gevolgtrekking als geheel is wel noodzakelijk: gegeven het ene (buiten in de regen lopen) kan het andere niet uitblijven (nat worden). Toegepast op Gods besluit van verkiezing en verwerping: de toestand van het verkoren of verworpen zijn op zichzelf is niet noodzakelijk, en ook het besluit daartoe ligt in Gods vrijheid. Maar áls God van persoon X besluit dat hij of zij verkoren is tot eeuwig heil, dan kan het gevolg ook niet missen. Hetzelfde geldt voor persoon Y die voor eeuwig verloren gaat: Gods eeuwig besluit van verwerping kan niet veranderd worden, en toch is er van dwang geen sprake en gaat persoon $Y$ door eigen schuld verloren.

15 Zie bijvoorbeeld Michael Allen, Reformed Theology, Londen-New York 2010, 102-103, en verschillende bijdragen in David Gibson en Jonathan Gibson (red.), From Heaven He Came and Sought Her: Definite Atonement in Historical, Biblical, Theological, and Practical Perspective, Wheaton 2013. 
In deze structuur is verkiezing nadrukkelijk onvoorwaardelijk, zij gaat geheel van God uit, en rust niet op ons geloof als conditie - juist omgekeerd. Het is genade om genade te ontvangen. Er is niets in onszelf dat ons daarvoor kwalificeert of ons daarvoor voorsorteert. Met een verwijzing naar Efeziërs 1:4 benadrukt hoofdstuk I, artikel 9 dat wij worden uitgekozen niet ómdat wij heilig waren, maar ópdat wij heilig en onberispelijk zouden zijn. In de remonstrantse heilsorde is de structuur fundamenteel anders. Volgens Arminius en de zijnen kiest God die mensen uit van wie Hij tevoren ziet dat ze zullen geloven en volharden. Impliciet is hiermee de menselijke geloofskeus tot de voorwaarde gemaakt die Gods besluit van verkiezing bepaalt. ${ }^{16}$ De remonstrantse denkstructuur draait om de rationeel-morele instemming van de mens, en veronderstelt dat de mens vanuit zichzelf in staat is om van de middelen die God aanbiedt om tot geloof te komen het goede gebruik te maken. Daartegenover staat in de Dordtse Leerregels de radicale omzetting van de menselijke wil in het wonder van de wedergeboorte centraal.

Op dit punt konden de Leerregels weleens actueler zijn dan in de tijd waarin ze geschreven werden, omdat in onze huidige cultuur de wil met haar autonomie een vanzelfsprekendheid is geworden. Wat zich in de vroegmoderne beweging van Arminius en anderen aankondigt, is vandaag de dag gemeengoed geworden. ${ }^{17}$ Maar wat dóet de menselijke wil nu eigenlijk, aan goed of kwaad? Die vraag verdwijnt soms naar de achtergrond, en dan wordt 'willen' een hoogstpersoonlijke maar irrationele drang waar verder niets over te zeggen valt. Mensen verschuilen zich achter het enkele feit van hun persoonlijke keuze. Vanuit het evangelie mogen wij een spade dieper steken: Waartoe leidt al dat willen en kiezen van ons? Hoe bereiken wij het goede? Hoe kunnen wij mensen worden die naar God toegewend leven? Voor die diepte blijft het van wezenlijk belang om aan de grote structuur van de Dordtse Leerregels vast te houden: het heil, het goede, komt niet van ons. Wij kunnen wel het kwade willen, maar van heil en verlossing is alleen Gods eeuwig raadsbesluit de bron.

16 Arminius zelf presenteerde in de 'Verklaring van gevoelen' een viervoudig besluit van verkiezing, beginnend bij (1) de voorafgaande verkiezing van Christus tot Middelaar, via (2) het besluit om diegenen te verkiezen die tot geloof in Christus komen, en (3) het besluit om de daartoe nodige middelen te verstrekken, tot (4) de uiteindelijke individuele verkiezing van wie deze middelen goed gebruiken. Uitgebreide bespreking van deze vier-decretenleer bij Dekker, Rijker dan Midas, 178-231.

17 Op deze thematiek gaat het artikel van Labooy in dit nummer nader in. 
Een apart element in de conceptuele structuur van de Canones betreft de dynamiek van eeuwigheid en tijd. De Leerregels maken niet met zoveel woorden duidelijk wat ze met het woord 'eeuwig' bedoelen, maar vanuit de theologie rond de Dordtse synode zou ik deze invulling willen voorstellen: de eeuwige God is van een andere orde dan schepselen in de tijd; zijn bestaan is van een andere categorie. We krijgen kortsluiting als we 'eeuwig' opvatten alleen in de zin van 'voorafgaand aan'. Eeuwigheid is Gods unieke wijze van zijn en handelen die oneindig onze bestaanswijze te boven gaat. ${ }^{18} \mathrm{Er}$ is eenheid in Gods handelen ván zijn eeuwig besluit náár zijn werk van verlossing in de tijd en de actuele verkondiging van Gods beloften. Zijn besluit is zeker en onveranderlijk (I, 11), en tegelijk is zijn appèl op ons volstrekt serieus, zoals hoofdstuk III/IV, artikel 8 het verwoordt: 'zovelen als er door het Evangelie geroepen worden, die worden in alle ernst geroepen.' Het blijft de moeite waard om te overwegen hoe Dordt deze dynamiek van eeuwigheid en tijd, van onveranderlijke verkiezing en krachtdadige roeping, onder woorden brengt.

\section{Motieven}

Het derde en laatste onderdeel van dit artikel gaat over de motieven die in de Dordtse Leerregels te herkennen zijn: de diepere drijfveren die in de uiteenzetting van de leer gestalte krijgen. Juist op dit niveau komt de actualiteit van de Leerregels het sterkst naar voren. Ook als de vorm waarin Dordt deze motieven uitwerkt de sporen draagt van een debat en een denkstructuur die niet zonder meer de onze zijn, dan nog spreken de Leerregels diepere spirituele en bijbelse lagen aan.

Een belangrijk soteriologisch motief is al genoemd: genade. Het heil komt niet uit ons, maar uit God alleen. Had Hermann Friedrich Kohlbrugge gelijk

18 Zie bijvoorbeeld de omschrijving van Gods eeuwigheid in de Leidse Synopsis purioris theologiae, disputatie VI, stelling 28 (in de recente Engelse vertaling van Dolf te Velde e.a. (red.), Synopsis purioris theologiae / Synopsis of a Purer Theology, dl. 1: Disputations 1-23, Leiden-Boston 2014, 167: "Eternity is an attribute of the duration assigned to the essence of the infinite God, whereby his being is exempt from a temporal terminus a quo, a beginning, and a terminus ad quem, an ending; it is also free of any succession (i.e., former and latter), of bygone and future time. Accordingly the essence of God is now, and has been before now and shall be hereafter, and each of these infinitely, to such an extent that it embraces all parts of time at once, indeed that it surpasses all time - no rather, that it is unaffected by time." Een hedendaagse doordenking van de eeuwigheid van God wordt geboden door Bert Loonstra, God schrijft geschiedenis. Disputaties over de Eeuwige, Zoetermeer 2003, 107-113, 153-162 en Willen en voelen en uitverkiezing. Hoe Arminius en Dordt nader tot elkaar kunnen komen, Amsterdam 2016, 90-100. 
met zijn verwijt ${ }^{19}$ dat Dordt op de rechtvaardiging van de goddeloze had moeten inzetten? Ik zou willen antwoorden: ja en nee. Ja: in de leer van de rechtvaardiging komt de radicaliteit van Gods genade het scherpst tot uitdrukking. Tegelijk kunnen we ook antwoorden: nee, want in termen van zonde - verkiezing - verzoening - wedergeboorte heeft Dordt ditzelfde motief magistraal vastgehouden. Het zou er niet wezenlijk anders van zijn geworden als het conflict was beslecht via de leer van de rechtvaardiging.

Vervolgens noem ik een christologisch motief. Daar zijn wel vragen bij te stellen: staat Christus werkelijk centraal in de leer van de uitverkiezing zoals Dordt die presenteert? Soms is geopperd dat de Dordtse orthodoxie op dit punt zwakker staat dan Arminius, bij wie Gods verkiezingsbesluit draait om Christus. Toch geloof ik dat hier de schijn bedriegt. Als het erop aankomt, heeft Christus juist bij Arminius een externe, extrinsieke betekenis: Hij brengt de mogelijkheid van verlossing binnen ons bereik. De voldoening door Christus wordt door Arminius aangemerkt als de 'verdienende oorzaak' die God motiveert tot zijn besluit van verkiezing, maar deze voldoening krijgt pas effect wanneer wij die met ons geloof aannemen. De Dordtse Leerregels zien er (in I, 7) bewust van af om Christus het 'fundament van de verkiezing' te noemen. ${ }^{20}$ Dit is niet omdat Hij er geen wezenlijke rol bij vervult: de Zoon van God is als één van de Drie-eenheid constitutief voor het geheel van verkiezing en verlossing. God hoeft niet van buitenaf bewogen te worden tot onze verlossing, want Hij komt vanuit zichzelf in beweging. In hoofdstuk II blijkt dit ook als over de waarde van de dood van Christus wordt gesproken. Deze waarde is intrinsiek (II, 4): 'En deze dood is daarom van een zo grote kracht en waarde, omdat de persoon die haar heeft ondergaan, niet alleen een waarachtig en volkomen heilig mens is, maar ook de eniggeboren Zoon van God, van hetzelfde eeuwige en oneindige wezen met de Vader en de Heilige Geest, zoals onze Zaligmaker moest zijn.' Ook in dit opzicht zijn de Leerregels volop actueel in een tijd waarin velen opnieuw zoeken de intrinsieke betekenis van de verzoening te verstaan. ${ }^{21}$

19 In een brief die Kohlbrugge in 1835 schreef aan zijn vriend Van Heumen, opgenomen in J. van Lonkhuijzen, Hermann Friedrich Kohlbrugge en zijn prediking, in de lijst van zijn tijd, Wageningen 1905, Bijlage B, 22-25.

20 Op deze formulering gaat Graafland, Van Calvijn tot Barth, 146-148 uitvoerig in.

21 Voor deze thematiek, zie bijvoorbeeld A.H. van Veluw, 'De straf die ons de vrede aanbrengt'. Over God, kruis, straf en de slachtoffers van deze wereld in de christelijke verzoeningsleer, Zoetermeer 2002, en Hans Burger, Reinier Sonneveld (red.), Cruciaal. De verrassende betekenis van Jezus'kruisiging, Amsterdam 2014. 
We kunnen bij de Dordtse Leerregels ook spreken van een bijbels motief: binnen de gegeven kaders die door de polemiek met de remonstranten zijn bepaald, valt het hoge gehalte aan bijbelse formuleringen en verwijzingen op. Een van de manieren om de Leerregels te lezen, is als een rangschikking van bijbelse gegevens. Uiteraard komen de schriftgegevens naar voren in een bepaalde samenhang en met een duidelijke strekking, maar is dat niet onvermijdelijk? Het gesprek over het bijbelgebruik in de Canones zal op de inhoudelijke plausibiliteit van het beroep op de Schrift moeten ingaan. ${ }^{22}$ Het is van belang om de bijbelcitaten niet als losse 'bewijsteksten' te interpreteren, maar terug te vragen naar de bredere traditie van gereformeerde bijbeluitleg van die tijd.

Opvallend is vervolgens het pastoraal-existentiële motief: de Dordtse Leerregels gaan diep en reëel in op wat er in een mensenleven en een mensenhart gebeurt. In de uiteenzetting van de bijbelse leer willen de Canones tot zekerheid en tot vertrouwen brengen. Er is oog voor de vragen en onzekerheden die bij de gelovigen kunnen opkomen, en ook voor de verschillende wegen waarlangs de zekerheid van het heil tot stand komt. In verschillende hoofdstukken vinden we concrete adviezen over wat daarbij kan helpen. Zit Dordt hiermee op een riskant spoor? Wel als de 'weg naar binnen' wordt ingeslagen, als zekerheid van de verkiezing een punt op zichzelf wordt, buiten de verkondigde Christus om. In de latere geschiedenis van Nadere Reformatie en gereformeerd piëtisme is gebleken dat dit risico er inderdaad is. Wanneer we echter nauwkeurig naar de Leerregels luisteren, merken we hoe Dordt zelf het tegenwicht aanbrengt door constant te wijzen op Gods betrouwbare beloften (I, 16; II, 5; III/IV, 17; V, 9-10,14). Er is geen sprake van dat de innerlijke bevinding hier wordt losgemaakt van de uitwendige en krachtdadige roeping door het evangelie.

Ten slotte: is er een kerkelijk en misschien zelfs missionair motief? Wat betekent deze leer van verkiezing en wedergeboorte voor ons kerk-zijn in de huidige tijd? Levert het een naar binnen gekeerd christendom op? Toegegeven, de aandacht wordt gericht op de binnenkant van het heil: wat gebeurt er met een mens? Toch speelt daar de realiteit van kerk en verkondiging als een vanzelfsprekend kader omheen. De wereldwijde verbreiding van het evangelie is in beeld: het moet zonder onderscheid aan alle volken en mensen verkondigd worden (II, 5). De (twijfelende) gelovige is aangewezen op de genademiddelen van verkondiging en sacramenten, waarin God zijn heil bij ons thuisbrengt. Juist het inzicht dat onze verlossing volledig van God komt en niet 
van ons, opent een geweldig perspectief voor verkondiging en zending tot in de verste uithoeken. God is het die met zijn genade ons opzoekt, en met ons al het verlorene. We kunnen verlossing en eeuwig leven niet als een privilege voor onszelf houden, omdat het Gods grote geschenk is waarop wij geen enkel recht hebben. Op een verrassende manier komt de kerk ter sprake in het laatste artikel van de Leerregels $(\mathrm{V}, 15)$, waar het gaat over 'de bruid van Christus'. De leer van de volharding heet daar 'een onwaardeerbare schat' die door de bruid innig liefgehad en standvastig verdedigd wordt. Van daaruit teruglezend zou je kunnen zeggen: in de Leerregels ging het om de kerk, niet om het gelovige individu. Zo ziet hoofdstuk II, artikel 9 Gods werk van verkiezing erop uitlopen 'dat er een kerk van gelovigen zal zijn, gefundeerd in het bloed van Christus, die haar Zaligmaker - die voor haar, als een bruidegom voor zijn bruid, aan het kruis zijn leven gegeven heeft - standvastig bemint, onafgebroken dient en hier en in alle eeuwigheid prijst.' Verkiezing en volharding krijgen in de kerk als gemeenschap van heiligen gestalte. De bruid die haar schat bewaart, is tegelijk de schat die bewaard wordt voor haar Bruidegom. Deze dubbele schat ligt in de Leerregels van Dordt opgetast, en die schat blijft ook in de $21^{\mathrm{e}}$ eeuw zijn waarde behouden.

R.T. te Velde is universitair docent systematische theologie aan de Theologische Universiteit Kampen, en tevens verbonden aan de Evangelische Theologische Faculteit Leuven (België).

* Dit artikel is een bewerking van de lezing die ik op 4 januari 2018 hield voor de contio van predikanten uit de Gereformeerde Bond in de Protestantse Kerk in Nederland. 